12 MYOCARDIAL VIABILITY IN PRESERVED OR MILDLY IMPAIRED LEFT VENTRICULAR FUNCTION PRIOR TO REVASCULARISATION - FINDINGS FROM A 3 YEAR EXPERIENCE

${ }^{1} \mathrm{H}$ Douglas, ${ }^{1} \mathrm{~B}$ Cole, ${ }^{2} \mathrm{CM}$ Soong, ${ }^{2} \mathrm{M}$ Harbinson, ${ }^{3} \mathrm{P}$ Horan, ${ }^{1} \mathrm{U}$ Dixon, ${ }^{1} \mathrm{~N}$ Johnston. ${ }^{1}$ Cardiology Department, Royal Victoria Hospital, Belfast, Northern Ireland, UK; ${ }^{2}$ Queen's University, Belfast, Northern Ireland, UK; ${ }^{3}$ Cardiology Department, Antrim Area Hospital, Antrim, Northern Ireland, UK

\subsection{6/heartjnl-2015-307845.12}

Background Viability assessment prior to revascularisation at our institution is largely requested for patients with severely impaired left ventricles (LV). This study however aims to review the outcomes of those patients with preserved or mildly impaired LV function who underwent cardiac magnetic resonance imaging (CMR) for assessment of viability prior to revascularisation and to evaluate its use in this group.

Methods All patients undergoing CMR to assess viability prior to coronary artery revascularisation were identified and included from January 2011 until June 2013.

Results Viability assessments were undertaken in 256 patients who were referred for revascularisation by either percutaneous coronary intervention (PCI) or surgery. Of these 71 (27.7\%) were found to have preserved or mildly impaired LV function, defined by an ejection fraction (EF) greater than 45\% (72\% male, mean age $66 \pm 12.8$ years). Adenosine stress perfusion was performed in $25.4 \%$. Twenty four percent of patients were turned down for revascularisation. Mean LV measurements within groups were as follows: EF CABG $56.67 \pm 7.58 \%$, PCI $57.41 \pm 8.58 \%$, medical management $59.4 \pm 19.65 \%(\mathrm{p}=0.58)$, LVEDV CABG $87.74 \pm$ $19.37 \mathrm{mls}$, PCI $85.22 \pm 20.62 \mathrm{mls}$, medical $80.41 \pm 16.14 \mathrm{mls}$ $(\mathrm{p}=0.47)$. The number of non-viable segments within each group was: CABG $2.15 \pm 1.99$, PCI $2.15 \pm 2.13$ and medical $2.41 \pm 2.06(p=0.90)$. The nonviable segments were in LAD territory in: CABG 22.2\%, PCI $33.3 \%$ and medical $29.4 \%$ $(\mathrm{p}=0.66)$. Median follow up was 2.4 years. Outcome data was follows; MACE: CABG 14.8\%, PCI 7.4\% and medical $11.8 \%$ $(\mathrm{p}=0.69)$; death: CABG $11.1 \%$, PCI $7.4 \%$, with no reported deaths in the medical management group $(\mathrm{p}=0.37)$; revascularisation: CABG 3.7\%, PCI 11.1\% and medical 11.8\% ( $\mathrm{p}=0.53)$. Conclusions Viability assessment by CMR has not been shown to have a significant impact on the management of patients with preserved or mildly impaired LV. We propose that stress perfusion for assessment of ischaemia would improve the utility of CMR in this group.

\section{CORRELATION OF INTERVENTRICULAR SYSTOLIC RELATIONSHIP AND INFARCT SIZE IN ACUTE MYOCARDIAL INFARCTION}

P Garg, A Kidambi, DP Ripley, LE Dobson, PP Swoboda, TA Musa, AK McDiarmid, B Erhayiem, JP Greenwood, S Plein. LICAMM, University of Leeds, Leeds, UK

\subsection{6/heartjnl-2015-307845.13}

Background In an echocardiographic study investigating interventricular systolic relationship in healthy individuals, the absolute value of tricuspid annular plane systolic excursion (TAPSE) is greater than the mitral annular plane of systolic excursion (MAPSE) by $54.5 \%$ and the MAPSE/TAPSE ratio is $0.66 \pm$ 0.14 . However, the interventricular systolic relationship has not been accurately defined in the presence of regional wall motion abnormalities. We hypothesised that the interventricular systolic relationship, measured by the ratio of averaged-MAPSE and
TAPSE, changes in the presence of acute myocardial infarction (AMI).

Methods Thirty-eight patients underwent CMR at 3T (Achieva CV, Philips Healthcare, Best, The Netherlands) within 3 days following AMI. Cine and LGE imaging (16-20 min following $0.1 \mathrm{mmol} / \mathrm{kg}$ gadolinium DTPA) were performed. Infarct location was determined by location of LGE in the infarcted area. MAPSE (medial, lateral and average) and TAPSE were measured from the 4-chamber cine (Figure 1). The infarct volume was measured from LGE images by Otsu method.

Results The MAPSE/TAPSE ratio in acute-MI patients was significantly reduced compared to reported normal values $(0.56 \pm$ 0.14 vs $0.66 \pm 0.14 ; \mathrm{p}=0.003)$. LV ejection fraction (EF) correlated most closely with averaged MAPSE ( $\mathrm{r}=0.45$; $\mathrm{p}=0.004)$. The interventricular systolic relationship significantly correlated with left ventricular end-diastolic indexed volume (LVEDVi) $(\mathrm{r}=-0.46 ; \mathrm{p}=0.009)$ and infarct volume $(\mathrm{r}=-0.36 ; \mathrm{p}=0.04)$.

Conclusion The ratio of averaged-MAPSE/TAPSE is significantly reduced in patients with acute-MI and correlates with infarct size. In cases where acute-MI is suspected, this parameter of interventricular systolic relationship may provide a simple additional diagnostic tool for both echocardiography and CMR assessment.

Funding JPG and SP receive a research grant from Philips Healthcare. SP is funded by British Heart Foundation fellowship (FS/10/62/28409).

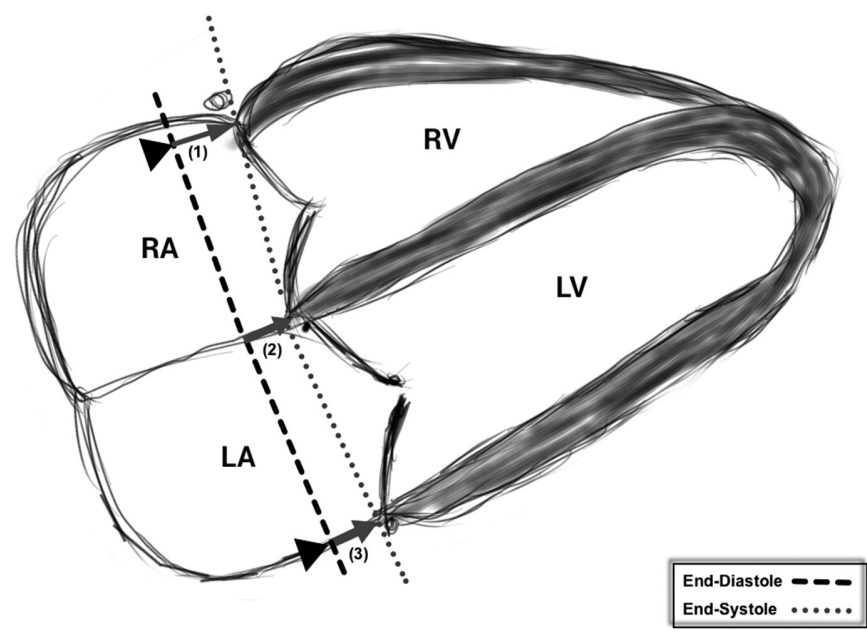

Abstract 13 Figure 1 Illustration demonstrating the three measurements. (1 - TAPSE; 2 - Medial MAPSE; 3 - Lateral MAPSE)

\section{FEATURE TRACKING VERSUS MANUAL METHODS OF ASSESSMENT OF LEFT ATRIAL MECHANICS IN ACUTE MYOCARDIAL INFARCTION: A PILOT STUDY}

P Garg, JRJ Foley, A Kidambi, DP Ripley, LE Dobson, PP Swoboda, TA Musa, AK McDiarmid, B Erhayiem, JP Greenwood, S Plein. LICAMM, University of Leeds, Leeds, UK

\subsection{6/heartjnl-2015-307845.14}

Background LA function is conventionally assessed by bi-plane method to compute LA end diastolic volume (LAEDV), end systolic volume (LAESV), stroke volume (LA SV), ejection fraction (LA EF). Voxel feature tracking (FT) is a novel technique for the assessment of LA function. We aimed to investigate if voxel FT derived longitudinal or radial strains are superior to traditionally 